\title{
Reporting Practices and Reported Entities
}

\author{
Nellie Wieland
}

\section{Introduction}

The starting point of this chapter is that when speakers report they make assumptions about the kind of linguistic entity being reported. This can be very roughly captured in the distinction between direct and indirect reports - or those about language and those about a state of affairs. Interestingly, speakers seem to operate with many more finely-grained distinctions. For example, to start with a simple case, when speaker $A$ says, in English and with an Italian accent, that it is raining outside, speaker $B$ need not report what $A$ said with an Italian accent because, presumably, the accent is not part of what A said. However, in another case, if the accent is not part of what $A$ said, it may still be what $B$ would like to report using what $A$ said as a more or less arbitrary vehicle for this report. Given this, discerning the semantic conditions governing what is said can only get us so far in a full understanding of reports.

Before going forward, it is worth defending this approach to analyzing reports. Speakers use expressions like 'said that' in fairly liberal ways, and it is unlikely that they do so in ways that are semantically faithful. So, we might think that an analysis of speakers' use of, for example, 'said that' does not reveal anything interesting about linguistic reality - but instead merely reveals speakers' conceptions of linguistic reality - unless it is the case that linguistic reality only consists of speakers' conceptions of language and their use of language (in addition to other subpersonal facts about those same speakers). This paper is not the place to sort out these kinds of meta-theoretical issues. But it is worth investigating the variety of speakers' reports as possible data, even if we do not take them as incontrovertible evidence for somesuch view.

\footnotetext{
N. Wieland $(\triangle)$

Department of Philosophy, California State University, Long Beach, CA, USA

e-mail: nellie.wieland@gmail.com
} 


\section{Reporting as an Ability}

It is assumed that reporting is a complex ability, and one that draws on multiple cognitive functions. Different abilities are brought to the fore depending on what a reporter is attempting to accomplish. Some of what a reporter needs to be able to do includes:

- An ability to understand and represent the locutionary content of the speech being reported.

- An ability to understand and represent the illocutionary content of the speech being reported. For example: in order to faithfully report, a reporter should understand whether the speech being reported was uttered figuratively or sarcastically.

- An ability to represent the way in which the original utterance was produced. For example: in a loud or soft voice, with an accent, with hesitation.

- An ability to have a theory of mind for both the speaker being reported and for their audience (Cummings 2015).

- An ability to organize the above functions in a kind of narrative structure (Norrick 2015). This structure is, in part, what permits movement between kinds of reports (direct, indirect, mixed) as long as adequate markers are present to guide the hearer. These markers may be syntactic, semantic, pragmatic, and prosodic.

On the other side, a corresponding set of cognitive functions is required by the audience in order to demarcate that which is being produced by the reporter and that which is being imported from the original utterance. This demarcation needs to be navigated for syntactic, semantic, pragmatic, and prosodic elements of the report. For example, the audience needs to understand when a reporter is sarcastically reporting the original utterance, and when a reporter is reporting a sarcastic utterance.

It is possible that philosophical confusion about quotation and other kinds of reporting results from isolating certain features of the larger structure of an exchange, given the complexity of the abilities involved in producing and interpreting reports. ${ }^{1}$ For example, to use one of the most common examples in the philosophy of language, if we say:

(1) "Bachelor has eight letters" is false, and

(2) “"Bachelor' has eight letters" is true

we might be posturing as if there is a peculiarity about quotation in natural languages when in fact we are not analyzing natural linguistic events in this example. In natural settings, (1) and (2) would be marked in various ways to eliminate confusion: using air-quotes or other framing gestures when uttering the term 'bachelor', raising or

\footnotetext{
${ }^{1}$ This confusion also arises from treating pure quotations as phenomena similar to other kinds of reporting practices. They ought to be treated as different in kind, despite the fact of their shared use of quotation marks; they are not operating according to the same linguistic mechanisms. See discussion in Sect. 3 for additional remarks.
} 
lowering the voice when uttering a portion of the sentence (Holt 2015), assuming certain background knowledge on behalf of the audience (e.g., that we never talk about how many letters people have, but we ordinarily talk about how many letters words have).

\section{Terminology of Reporting Practices}

Reports can be divided up in a few ways. ${ }^{2}$ Direct reports are faithful representations of what a speaker said as the speaker said it. Ideally, direct reports do not deviate from the linguistic form of the original utterance (although it is assumed that they survive translation across languages). They should not paraphrase the original utterance, nor should they alter tense or indexicality. In written discourse, they are usually marked in English with quotation marks. Written direct reports in English can also be marked in other ways as well-including with dashes, italics, and line breaks. Across languages, there are, of course, variations in both punctuation as well as the expectations governing the felicity of direct reports to their original source. ${ }^{3}$

Indirect reports allow for some amount of paraphrase and require shifts in tense and indexicality. ${ }^{4}$ In written discourse these are marked through a variety of phrases (cognates to 'said that $p$ ') and are not uniformly marked with any form of punctuation.

Mixed reports are usually understood as combinations of the forms of direct and indirect reporting. For example, the overall structure of the report might be indirect, even though certain terms or phrases might be set apart as direct quotes for various reasons. ${ }^{5}$

Free indirect reports typically have a third-person construction and are common in literary works and ordinary acts of storytelling. These kinds of constructions move between direct and indirect reports; for instance, they adopt the narrative perspective of the original speaker without adopting that speaker's grammatical perspective. These are more complicated than the first three categories introduced in this section, so a few examples are in order to illustrate:

\footnotetext{
${ }^{2}$ I do not include pure quotation on this list because it's not a proper reporting practice. Instances of pure quotation involve using language to talk about a piece of language (e.g., "'Bachelor' has eight letters") rather than to report an utterance.

${ }^{3}$ See Maier (2015) for examples from ancient Greek. See also Schlenker (2011).

${ }^{4}$ There are interesting exceptions to this. Consider Ann Banfield's (1973) examples:

(i) Mary said yesterday that she would be in Chicago (by) now.

*(ii) Mary said yesterday that she is in Chicago (by) now.

${ }^{5}$ For a helpful overview, Maier (manuscript draft).
} 
(3)

Mrs. Dalloway said she would buy the flowers herself.

For Lucy had her work cut out for her. The doors would be taken off their hinges;

Rumpelmayer's men were coming. And then, thought Clarissa Dalloway, what a morning fresh as if issued to children on a beach.

What a lark! What a plunge! For so it had always seemed to her when, with a little squeak of the hinges, which she could hear now, she had burst open the French windows and plunged at Bourton into the open air. How fresh, how calm, stiller than this of course, the air was in the early morning; like the flap of a wave; the kiss of a wave; chill and sharp and yet (for a girl of 18 as she then was) solemn, feeling as she did, standing there at the open window, that something awful was about to happen; looking at the flowers, at the trees with the smoke winding off them and the rooks rising, falling; standing and looking until Peter Walsh said, 'Musing among the vegetables?' - was that it? 'I prefer men to cauliflowers'-was that it?

In this case, the passage portrays the direct narrative perspective of the speaker, in some lines of her reflecting on her own thoughts, with the indirect reporting of thirdperson narration. In the case where Peter Walsh's utterances are directly reported, they are followed by an interior reflection from Mrs. Dalloway's perspective. If we treat Virginia Woolf as the speaker, then she is engaged in free indirect reports of Mrs. Dalloway's thoughts and Peter Walsh's utterances. Here is another case:

(4)

Hurray! Tomorrow she would be home and she would never have to see this place again, she thought to herself. (Maier 2014, pg. 2)

Here again the narration is third-person, but the passage is written from the firstperson perspective of the character.

That there are multiple sub-categories of reporting practices suggests that reporters are likely to take different kinds of attitudes to the entity they take themselves to be reporting. A rough division would look something like this: since direct reports require faithfulness to the linguistic form of the original utterance, this indicates that speakers take themselves to be reporting a linguistic entity. They take their report to be de dicto or strictly about the linguistic form and content of an utterance. Indirect reports permit a range of transformations (under shifts in indexicality, tense, paraphrase, point of reference, etc.) (Wieland 2013; Capone, draft manuscript). This suggests that, in indirect reports, speakers take themselves to be reporting something non-linguistic or something indirectly linguistic. In most such cases speakers take themselves to be reporting what was meant rather than what was said. Both mixed reports and free indirect reports involve aspects of direct and indirect reports to varying degrees. It depends on whether the governing structure of the report is direct or indirect in determining whether the report will involve significant transformations. Similarly, it will depend on this governing structure whether the speaker will primarily take herself to reporting a linguistic entity. For example, unquotation - which is a variety of mixed quotation-is described (Maier 2014, 2015 manuscript draft) as a case when an utterance is directly reported but with gaps where the original utterance is deviated from or omitted. In this case, it

${ }^{6}$ Woolf (1969); quoted and analyzed in Banfield (1973). 
seems right to say that the report is about a linguistic entity, even if it has an indirect frame superimposed on the direct report, and the audience is expected to recognize that this is what the report is transmitting, even given the deviations. In cases of mixed reports that have an indirect governing form and only insert the occasional directly quoted word or phrase, it seems likely that the reporter takes herself to be reporting something non-linguistic (such as information or a state of affairs), or indirectly linguistic (i.e., using a paraphrased locution in order to convey that which is non-linguistic).

This set of distinctions drawn from the basic terminology of reporting practices is still quite general. It does not reflect the variety of speech acts speakers use reports to perform. This claim is explained in the next section.

\section{Conceptions of Language}

Reporters take themselves to be performing a variety of tasks when they report. Each of these tasks can take a different object. Philosophers of language, in particular, have adopted a narrow interpretation on the task of reporting. The narrow interpretation is that reporting is an entirely linguistic event, and linguistic events are exhaustively syntactic, semantic, and, to an extent, pragmatic. Speakers do not behave in ways that reflect this narrow interpretation. Whether or not they regard a report as a linguistic event narrowly construed depends on their conversational goal. Speakers are sometimes interested in linguistic accuracy, and sometimes in storytelling or recreation of mood or feeling, and sometimes in exploitation for the purpose of furthering a conversational goal (e.g., reporting for the purpose of irony or mocking).

The family of activities analyzed under the reporting headline is quite diverse. Examples of specific reporting goals include:

utterances used to talk about utterances:

(5) Mary asked, "why so many examples about bachelors?"

utterances used to ridicule:

(6) Pam said that she voted for Caribou Barbie.

utterances used to set a tone or mood such as in the use of an epigram:

(7) To love oneself is the beginning of a lifelong romance - Oscar Wilde utterances used to imitate (including in non-linguistic ways):

(8) And then he said, "I vill be back!"

utterances used to structure a story:

(9) And then she was like "no way!"

This final item on the list is one of the most interesting, and one of the most common. This kind of ordinary story-telling occupies a great deal of our conversational lives. 
This is described as "utterances used to structure a story" rather than "utterances used to tell a story" because reports are not used in story telling only to convey what is said, or even merely to convey non-linguistic information about what happened, but they can also be used to mark shifts in the story including changes in setting, changes in narration, changes in action, or provide commentary, punctuation, or interpretation to highlight aspects of the story.

This suggests that speakers take reported entities to be linguistic and nonlinguistic entities, ${ }^{7}$ depending on the needs and stipulations of the reporter. Only some of the actions that speakers are engaged in when they report are metalinguistic. But by referring to all of them as kinds of reports, it seems as if speakers in these contexts are all engaged in a kind of metalinguistic task, and the goal is to determine how the tasks can be unified in a single theory of reporting.

If speakers primarily took reporting to be a metalinguistic task-where the object of the report is merely a linguistic entity-then it seems like speakers would track the felicity of reports by their linguistic fidelity. Yet, fidelity is neither necessary nor sufficient for perceived felicity. What does this mean for how we think about metalinguistic concepts like same-saying, reporting, quoting, and shared content? Varieties of reporting practices tell us something about the pragmatics of the reporting setting, the reporter's goals, audience expectations, and even the possible parameters for contextual modification. But they could also tell us more about the original utterance, where it leaves itself open to transformation, and the ways in which linguistic and non-linguistic content interact in order to make available reportable content.

It is certainly the case that many reports contain the minimal propositional content of the original utterance in addition to a plurality of speech act content. But we do not need to assume this is the case for all reports. Speakers could instead index their reports to para-linguistic goals. A reporter might not report minimal semantic content, but might report the way something is said (e.g., with an accent, in a low voice, with a certain cadence). It is easy to dismiss this phenomenon as irrelevant to true, semantically significant reporting, same-saying, or even quoting, but it is difficult to do so in a way that is not circular-for example, by just assuming that reporting, same-saying, and quoting have one kind of content rather than another. Take a look at the following exchange (difficult to reproduce in written form):

\footnotetext{
${ }^{7} \mathrm{~A}$ note to explain the use of 'linguistic' and 'non-linguistic' here: the analysis of this paper is meant to hint at some metaphysical conclusions. These are that it might not be possible to exhaustively analyze the content of a report by linguistic means. The reporter might take her report to convey moods, feelings, or events in addition to linguistic content. Elsewhere I describe this as a problem of describing the individuation and containment conditions of language. Ben Caplan has suggested to me that I am actually interested in the individuation and containment conditions of content. In either case, the problem is how to determine the limits of the entity being reported and the extent to which it is linguistic (as ordinarily understood).
} 
A I love Paris in spring.

[sings]

$B_{1}$ : $\quad A$ said [singing] "I love Paris in spring."

$? B_{2}$ : $\quad A$ said [not singing], "I love Paris in spring."

We could imagine various reasons for $B_{1}$ 's report. Perhaps $B_{1}$ does not think that $A$ is a very good singer and $B_{1}$ wants to share a laugh with her audience about $A$ 's performance. Perhaps $B_{1}$ is using $A$ to model the correct notes to hit in a song. But it is less clear how felicitous $B_{2}$ 's report is. ${ }^{8}$ It is possible that $A$, so taken with Paris in spring, expressed her affection in song, and the affection was correctly reported in ordinary speech. But it is also possible that $A$ was singing for reasons other than communicating her beliefs in which case $B_{2}$ 's report feels inappropriate at best, or worse, false. We can see the incongruities of analyzing indirect reports with limited semantic criteria in this report from $C$ :

${ }^{*} C: \quad B$ reported that $A$ said that she loves Paris in spring. But this is false. Everybody knows that $A$ dislikes Paris in every season.

In most cases this report feels incongruous because speakers would recognize two things: $A$ is most likely not saying anything about her preference for Paris and its seasons; $B$ is most likely not reporting anything about $A$ 's preference for Paris and its seasons. And finally consider another possible report:

?D: A said, "I love Paris in spring," but said nothing about her affections for the capital of France.

This illustrates something similar to what Grice calls the 'cancelability principle'. He uses this principle in his determination of conversational implicature: if $q$ is an implicature of $p$ then we couldn't (or wouldn't) say $p$ and add, 'but not $q$ '. Similarly we might ask whether we can treat an utterance as quoted if we can reject its entailment in the very same report, as in the case of speaker $D$ in example (10). This example might show that $D$ 's utterance is felicitous despite being immediately canceled. (Admittedly, this intuition may be weak or atypical.)

What, if any, pragmatic explanations are available to explain how this plurality of practices can all be varieties of reports? There are two general ways of accounting for the plurality of attitudes speakers can take toward the object of their report. One way is to regard all reporting practices as metalinguistic, and then to regard that which does not appear to be metalinguistic as not an example of a proper report. ${ }^{9}$ A single semantic analysis such as this (which is perhaps still unsettled) says

\footnotetext{
${ }^{8}$ Neither may be a report. I don't know if singing can be reported. But it is interesting to consider whether it can be, and how.

${ }^{9} \mathrm{~A}$ discussion of this possibility can be found in Cappelen and Lepore (1997). Here they consider a view called $M A$ : "an adequate semantic theory $\mathrm{T}$ for a language should assign $\mathrm{p}$ as the semantic content of a sentence S in L iff in uttering S a speaker says that p" $(1997,278)$. They conclude that the plurality of ways that speakers use the locution 'said that' do not pose a problem for semantic theory (although they appear to have changed their view on this by Cappelen and Lepore (2007)).
} 
that whatever follows the that clause in some way refers to, demonstrates towards, echoes (etc.) the utterance being reported. In this case the analysis of reported entities would not follow the practices of speakers-regarding them as, perhaps, confused. A unified account would make the most of the similarity of structuree.g., the use of quotation marks, or phrases such as 'said that' to mark the varied reports.

The second way of accounting for the plurality of attitudes speakers can take toward the object of their report would be to treat reporting practices separately and offer semantic and pragmatic analyses for each. The pluralistic account would emphasize the differences in speech act, conversational goals, and contextspecificity. Wilson (2000) uses the expression "the exploitation of resemblances" to explain the cognitive processes in play when interpreting an indirect report. The interpreter takes into consideration some collection of clues that are linguistically encoded and takes into consideration contextual information that would lead to the most salient, least taxing interpretation.

The suggestion here is that reporting practices are not uniformly metalinguistic, so any single theory that approaches indirect reports from this assumption will misdescribe the practices themselves. However, this is not to say that the proper solution is to propose a semantic account of quotation and indirect reports, and then to suggest that speakers use reporting practices loosely or misunderstand the semantics of a phrase such as 'said that'. It is an open question whether the plurality of speakers' conceptions of reported entities calls for a plurality of analyses of indirect reports or for a unified account. It is worth emphasizing, again, that the unified account does not need to be semantic in its assumptions. The prospects and barriers to unification are assessed in the next section.

\section{Prospects for Unification}

Proposing a unified theory of reports is attractive, even despite the worries posed here. One of the reasons it is attractive is because any theory that is sufficiently inclusive of all of these kinds of reporting practices would need to have a similarly inclusive conception of language and linguistic entities. Linguistic entities (like meanings) would need to be situated in settings, contexts, stories (and so on) to be fully-realized, truth-evaluable entities. They would need to be constructed out of their situations, rather than despite them.

\footnotetext{
Instead, they concur that there are probably an indefinite number of correct indirect reports for any given utterance. They do not defend a formal mechanism for generating or explaining this but suggest, reasonably, that it will be governed by pragmatic constraints. In this paper I use variations on some of their examples, in part in order to illustrate the same point that there are indefinitely many correct indirect reports for any given utterance, my goal differs. I think the indefinite number should prompt reflection about how to individuate and contain the content of the original utterance; I'm neutral as to whether this is a proper concern for semantic theory.
} 
How we distinguish between different kinds of reports differs depending on what we think the reported entity could possibly be. Providing a view of this goes beyond the scope of this paper, but here are a few additional considerations followed by a tentative pragmatic suggestion for how unification would look.

Presumptively, there are reasons against a unified account of direct and indirect reports based on the examples of reporting practices presented here. To see this clearly, consider the difference between (11a) and (11b):

(11a) Oedipus cried out that he has done something horrible with his mother, but I won't repeat what he actually said.

?(11b) Oedipus cried out, "I have done something horrible with my mother," but I won't repeat what he actually said. (Banfield 1973)

(11b) is problematic because the speaker makes a claim to direct quotation and then cancels the implication of directness in the following clause. The speaker in (11a) is entitled to do this because the speaker makes no claim to direct reporting. This is not cancelability of content, as with example (10), but cancelability of the semantic force of quotation marks. Any unified theory of reporting practices would need to take into account the barriers to transformation, as well as to cancelability.

Could an account of the plurality of reporting practices account for the variety of transformations across content, speech act type, inference, implicature, and allow for the use of reports as vehicles for non-linguistic content? One possibility would be to treat the range of reporting expressions_- 'said that', 'cried out that', 'asked whether', etc.-as indexical predicative expressions. The idea here is that these expressions point to an initially unspecified aspect of the original content. Jane Heal describes this account of indirect discourse in this way:

Davidson's earlier proposal was that the 'that' of indirect discourse refers indexically to the particular utterance which follows it. The alternative view to be defended here is that a that-clause refers indexically to some non-particular item of which the particular utterance is an instance. (Heal 2001, 433; see also, Davidson 1968)

This is the best contender for a unified account of reporting practices. As Heal conceives of it, it resolves a number of puzzles about indirect discourse including the plurality of propositional content, translation, transformations, using the linguistic content as a vehicle to report or emphasize tone, temper, emotion, to teach knowhow, and the like. If the indexical predication is expanded further it can also predicate conversational devices, the elements of narrative structure, and changes in speech act, as in some of the examples discussed here. In this passage, Heal describes this kind of indexical predication as:

involv[ing] the use of an indexical expression not to refer to a particular, but rather to characterize or describe. Indexical predication may, consistently with this, be effected through indexical reference to a non-particular, for example, a colour, property, kind, action, number, etc. (Heal 2001, 435)

Using these assumptions about indexical predicative expressions, we can-in part, following Heal - treat quotation marks and frames such as 'said that' as indexical expressions, but one whose use and interpretation requires know-how. 
This kind of know-how captures the cognitive abilities introduced in Sect. 2 of this chapter. These are the abilities to track transformations, changes in speech act, and inferential relations. Importantly, this know-how also involves the ability to detect the metaphysical assumptions of the speaker: e.g., what does she think the boundaries of the report are? Is she using the report functionally in the telling of the story? Does she intend to report content, or tone, or mood? Treating the reporting frame ('said that') as an indexical predicative expression resolves readings of more difficult cases such as (6), (8), (9), and (10). It might be objected that this is a much more expansive view of reporting practices than most views, but it is no more expansive than what is allowed in the case of ordinary indexicals, and especially demonstratives.

It may seem as if this solution still leaves out cases like the resolution of (11), as well as the puzzles raised by free indirect reports and mixed reports, including unquotation. Although there is a bit to say about each of these cases separately, as a first pass we should think about the know-how involved here as a matter of discerning the appropriate frame for constructing and interpreting each kind of report. For example, in the case of the mixed report, the speaker and interpreter each need to discern the manner in which to integrate the semantic indexical reference of the entities captured in quotation marks with the non-semantic entities referred to only indirectly. If it is the case that the utterance is principally framed as indirect report, then this integration will involve some kind of translation between the nonsemantic aspects of the indexical reference and the semantic insertion (e.g., in the case where a single word or phrase is directly quoted in an indirect framing structure).

If it is the case that the utterance appears to be framed as a direct report, but with omissions-as in the case of unquotation-then the speaker and interpreter have the same kind of task before them: interpreting the quotation marks as indexical references to semantic content, while the omissions indicate that the supervening structure is being imposed by the reporter and does not bear fidelity to the semantics of the original utterance. In the case of free indirect reports and narrations that move between direct, indirect, and mixed reports, the cognitive ability required is the ability to impose interpretive frames for the character of indexical predication in each case.

\section{Conclusion}

The difference between clear cases of direct and indirect reports are examples where speakers take themselves to be performing different kinds of tasks. In the case of a direct report, the reporter takes the report to be de dicto; in the case of in indirect report the reporter takes the report to be about (something like) the attitude of the original speaker. In the mixed report, the attitude of the original speaker is reported, interpolated with some portion of the language used in the original utterance. The result is that the sentence in incomplete under both de dicto and de re interpretations. 
But if we re-think the tasks of direct and indirect reports as natural parts of language, mixed reports don't present themselves as a puzzle anymore. Reporters are merely interested in language that was used or what the speaker meant to say (or some such variation on this); so there isn't a puzzle when they combine the two of these in a mixed report.

It has been emphasized in this paper that reporting of all kinds involves a number of cognitive abilities including varieties of know-how. To borrow Heal's example, teaching movements in a dance choreography is an obvious case of transmitting know-how through indexical reference. But in these cases, the dance movements cannot (easily) be articulated into a linguistic symbol system. In cases where we report the speech of others, it seems obvious that their speech can be reported in a linguistic system, and so the indexical references are explicitly marked within this system. But this is what makes indirect reporting so interesting. As a kind of storytelling, there is more to be told than what can be said, and the report often takes on the reproduction of the earlier scene or context. So, in answer to the question of what speakers take themselves to be reporting in an indirect report, one possibility is that they take themselves to be reporting whatever is salient from the earlier context, including linguistic and para-linguistic events.

This paper has considered the possibility that speakers use reports for a wide variety of linguistic and non-linguistic tasks, and in doing so, make a range of assumptions about the kinds of entities that it is possible to report. The speculative conclusion considered here is that this range of entities cannot be fully captured by an analysis of the semantic function of quotation marks or the phrase 'said that' and its correlates. Instead, the range of entities will best be captured if all reports are treated as something like indexical predicative expressions such that quotation marks and phrases such as 'said that' demonstrate toward some-such entity made salient in context. ${ }^{10}$

\section{References}

Banfield, A. (1973). Narrative style and direct and indirect speech. Foundations of Language, 10(1), 1-39.

Capone, A. (2015). On the (complicated) relationship between direct and indirect reports. In A. Capone, F. Kiefer, \& F. Lo-Piparo (Eds.), Indirect reports and pragmatics. Dordrecht: Springer.

Cappelen, H., \& Lepore, E. (1997). On an alleged connection between indirect speech and a theory of meaning. Mind \& Language, 12, 278-296.

Cappelen, H., \& Lepore, E. (2007). Language turned on itself: The semantics and pragmatics of metalinguistic discourse. New York: Oxford University Press.

\footnotetext{
${ }^{10}$ The author would like to thank the Lewis \& Clark Philosophy Department and the audience at the American Philosophical Association Pacific Division Meeting (2014) for feedback on earlier versions of this paper. I would especially like to thank Ben Caplan for his helpful comments at the APA meeting.
} 
Cummings, L. (2015). Reported speech: A clinical pragmatic perspective. In A. Capone, F. Kiefer, \& F. Lo Piparo (Eds.), Indirect reports and pragmatics. Dordrecht: Springer.

Davidson, D. (1968). On saying that. Synthese, 19, 130-146.

Heal, J. (2001). On speaking thus: The semantics of indirect discourse. Philosophical Quarterly, 51(205), 433-454.

Holt, E. (2015). Indirect reported speech in interaction. In A. Capone, F. Kiefer, \& F. Lo Piparo (Eds.), Indirect reports and pragmatics. Dordrecht: Springer.

Maier, E. (2014). Language shifts in free indirect discourse. Journal of Literary Semantics, 43(2), 143-167. doi:10.1515/jls-2014-0010.

Maier, E. (2015). Reported speech in the transition from orality to literacy. Glotta, 91, 152-170.

Maier, E. Manuscript draft. Mixed quotation.https://sites.google.com/site/emarmaier/publications. Accessed 8 May 2015.

Norrick, N. (2015). Indirect reports, quotation, and narrative. In A. Capone, F. Kiefer, \& F. Lo Piparo (Eds.), Indirect reports and pragmatics. Dordrecht: Springer.

Schlenker, P. (2011). Indexicality and de se reports. In K. von Heusinger, C. Maienborn, \& P. Portner (Eds.), Handbook of semantics (pp. 1561-1604). The Hague: Mouton de Gruyter.

Wieland, N. (2013). Indirect reports and pragmatics. In A. Capone, F. Lo Piparo, \& M. Carapezza (Eds.), Perspectives on pragmatics and philosophy (pp. 389-411). Dordrecht: Springer.

Wilson, D. (2000). Metarepresentation in linguistic communication. In D. Sperber (Ed.), Metarepresentations: A multidisciplinary perspective (pp. 411-448). New York: Oxford University Press.

Woolf, V. (1969). Mrs. Dalloway. Middlesex: Penguin. 